\title{
Study on Efficiency of Resources Invested in Environmental Protection for Thermal Power Plants Based on Accounting Data
}

\author{
En-Zhu LI ${ }^{1, a,{ }^{*}}$, Yu-Jie XUE ${ }^{2, b}$ and Guan-Nan $\mathrm{LI}^{3, \mathrm{c}}$ \\ ${ }^{1}$ School of Accounting, Shandong University of Finance \& Economics, Ji'nan 250014, China \\ 2 Jinan Companies of Sunac China Holdings Limited, Ji'nan 250101, China \\ ${ }^{3}$ Shandong Companies of Kaiyuan Securities Co., Ltd, Ji'nan 250014, China \\ aemail: lez11513@163.com, bemail: xueyujie2011@163.com, 'email: Ign0785@163.com \\ *Corresponding author
}

Keywords: Accounting, Efficiency of Resources, Environmental Protection, Thermal Power Plant.

\begin{abstract}
There are many environmental pollution factors with producing electric energy in thermal power plants. Environmental protection is a prerequisite for the whole production; large quantities of resources should be invested into environmental protection for preventing environmental-pollution accidents. By this paper, the requirement of introducing the system of evaluation of efficiency, based on data of accounting, used for such environmental-protection resources, is discussed systematically. The features of the recommended evaluation method of DEA are also explained. This method of evaluation of efficiency may be used in all units of thermal power plants with possible environmental-pollution accidents in in thermal power plants and for estimating and reflecting the inefficiency of the resources invested in preventing environmental-pollution accidents. On the basis of the functions of this evaluation system, the main framework of Data Envelopment Analysis (DEA) for the system of evaluating efficiency is also suggested, which is accordant to features of data of accounting in thermal power plants. The purpose of this research is to help effective management of resources invested into environmental protection.
\end{abstract}

\section{Introduction}

In the entire process of producing electric energy in thermal power plants, the impact of various emissions on the environment exceeds a certain limit, causing deterioration of the ecological quality. These emissions, being harmful substances to health of humen being and environment, include dust, ash, and flue gases, such as $\mathrm{SO}_{2}$ and NOx, emitted from the combustion process of the fuels; waste water and fluids discharged from various types of the thermal power plant equipment during operation [1], as well as noise emitted during operation of equipment's in the power plant. Environmental protection is a matter of key importance for electric energy production [2] and for sustainable development of industry, also a symbolic representation of social civilization and progress, and becomes more and more seriously, and changes into a common difficult question in China. The system of evaluating the efficiency of the resources supplied in ecological protection exits reasonably for reaching the objective of environmental protection. Many scholars proposed their research opinions of environmental protection from many angles in China and the world. These theories have played an important role in environmental protection for many kinds of units and enterprises, especially for thermal power plants. Thermal power plants have been listed in industry of high environmental pollution in China. The fact that many sciences and technology should be united to resolve the problems of environmental pollution in production of electric energy is proved. This paper will briefly discuss the innovation of advanced method for evaluating efficiency of resources invested into ecological protection based on information of accounting. 


\section{Necessity of Establishing System of Evaluating Efficiency}

\section{Requirement of Sustainable Development for Industry of Electric Energy}

In 1992, the World Commission on Environment and Development (WCED) defined the sustainable development formally. Sustainable development means the development that meets the needs of the present without compromising the ability of future generations to meet their own needs. Human is the subject of social existence and development, and human's need includes various aspects. In sustainable development, not only economic growth, but also resource, environment, social progress and the all-round development of human are the indexes to evaluate development. Similar to all the things, the production of strong continuity and environmental specificity makes ecological and stable operation is very important for the thermal power plants. No environmental-pollution accidents in production is the most basic guarantee of obtaining the maximum return for every thermal power plants, so investment of environmental-protection resources is the most important investment to produce electric energy and create profit, also is the most basic requirement for sustainable development for one of the thermal power plants and for industry of electric energy.

\section{Enlargement of Application of Accounting Data}

In order to guarantee the normal and ecological running of productive activity, the function of technology of accounting information also expands gradually. The accounting date can play an important role in more and more fields, and the information of accounting is providing service for many objects now. Under the guidance of theory of accounting, systematically researching the system for economic effectiveness of environmental-protection resources used to promote ecological protection in the thermal power plants on data of accounting will be a new field of study.

\section{Requirement of Enlargement of Environmental-protection Resources}

In the era of knowledge economy, people depend on excellent environment intensely and demand on ecological protection urgently [3]. The personal health threats and great economic loss caused by environmental-pollution accidents make human pay more attention to the economic meaning of environmental-protection. When attaching importance to the meaning of life and health, social benefit and economic loss should be paid attention to. Instability of raw materials, such as difference of the content of harmful elements in coal, greatly increases the possibility of occurrence of environmental pollutions. Accidents in environmental pollution not only affect the normal production of the thermal power plants, and even cause serious health damage of workers and inhabitants. It is necessary to establish long-term effective mechanism of environmental protection in such enterprises, construct the financial management and economic evaluation system of the resources invested and maintain interests of enterprise of thermal electric power, employees and social public. Expenses for environmental protection is the special capital used to improve the conditions of ecological production of the thermal power plant, the capital should be set aside according to the standard and be listed in the cost of the thermal power enterprise.

\section{Explanation of Economic Efficiency in Resources of Environmental Protection}

Although the resources supplied to environmental protection greatly increase in the thermal power plants recent years, Information from domestic and international organizations indicate that accidents of environmental pollutions still has become a significant problem because of the unsuccessful investment of such resources. Such accident also causes great harm to economy and sustainable development. "Smog event" is the expressions of inefficiency in investment of resources of environmental protection in China. In January of 2017, four smog processes enveloped 30 provinces (autonomous regions and municipalities). In Beijing, only five days were not foggy days. At the end of 2017, Shanghai, Nanjing and other central regions of China suffered the most severe areas. Shanghai has repeatedly seen PM2.5 index exceeding 500. According to reports, less than $1 \%$ of China's 500 largest cities meet the World Health Organization's recommended air quality standards. At the same time, 7 of the 10 most polluted cities in the world are in China [1]. With the improvement of living standard in China, people's demand on excellent environment is becoming higher and 
higher. Accordingly, the situation of high-frequency accidents of environmental pollutions has influenced the development of many kinds of industry seriously; especially the industry of the thermal power plants in China, industry of producing electric energy is China's main foundation of national economic and social development. So this industry must develop persistently, steadily and healthily. Environmental protection is the ultimate guarantee of electric energy industry's stable, persistent and fast development.

\section{Stipulations of Forming Evaluation System}

\section{Refining Mode of Disclosure in Accounting Information}

The refined disclosure form of accounting information is completely different from the traditional mode of accounting. To realize full utilization of resources of environmental protection, maximally improvement of the quality and benefits of such resources are the targets of accounting information disclosure in capital market. Forming the system of evaluating economic efficiency for environmental-protection resources makes higher demands on accounting form of information disclosure, the financial data related to environmental-protection resources should be real, accurate, timely, convenient, applicable and practical, and should not only reflect the actual situation, but also predict the future. Accounting should not only provide internal information, but also provide relating external information; there should be monetary information, and non-monetary information, which are the report forms of "products" of accounting. The present disclosure form of single pattern in accounting should be changed, and the content of environmental-protection resources should be disclosed in the report system to meet the need of economic evaluation.

\section{Setting the Related Standards of Accounting}

The financial data used in this system is the information about the working of environmental-protection resources in such enterprises. The following principles should be paid attention when choosing the information disclosure form in environmental-protection resources. Firstly, the least amount of relating information disclosed should be prescribed by the national related accounting standards. Secondly, the mechanism of disclosing such information voluntarily should be established for the thermal power plants. Thirdly, the accounting information of environmental-protection resources and the practical information should be combined. The financial statement, annotations of the statement and the report of financial situation of such enterprises should reveal the influences of environmental-protection problems on finance; on the other hand, the utilization status of environmental-protection resources can be provided by special "Report of Rnvironmental-protection Resources”.

\section{Main Framework of the Proposed Method}

\section{Method of Evaluation}

Because of the fluctuation in economic effectiveness and the lack of transparency in information of the environmental-protection resources, it is necessary to analyses the rationality of the supply of environmental-protection resources in the thermal power plants. In order to study the effects of every factor of evaluation system of environmental-protection resources mentioned above, method of Data Envelopment Analysis (DEA) in operational research will be proposed to evaluate the economic efficiency of environmental-protection resources invested in the thermal power plants [4]. The basic unit of Data Envelopment Analysis is Decision-Making Units (DMUs) [5]. DEA means a system or an activity that can transfer a series of input factors of resource or factors of evaluation of environmental-protection resources to a series of outputs for making decisions. The Data Envelopment Analysis (DEA) evaluates Decision Making Units (DMU) by using the mathematical programming pattern comparing relative efficiency between DMUs. Because it evaluates DMU from the best angle and need not any obvious relation between inputs and outputs, it is very objective [6]. 
The necessary data for method of DEA comes from the financial data chose carefully from accounting information. The Figure 1 illustrates the flow chart of DEA evaluation for this evaluation.

\section{Formation of the DEA Model for Evaluation}

The efficiency of a Decision-Making Units of DEA, the weighted-value variable of input factors of accounting information of environmental-protection resources and the weighted-value variable of output for decision are separately represented by $z^{t}, v_{i}^{t}$ and $u_{j}^{t}$ in a decision-making unit (suppose to $t$ ). The following $C^{2} R$ model of mathematical programming can calculate those three decision variables, as in model (4). There are $N$ decision-making units for evaluating the environmental-protection resources invested in this model (4) of mathematical programming. There are $I$ kinds of input factors of accounting date and $J$ kinds of outputs in every decision-making unit. According to modern accounting theory and the needs of evaluate risks, the main input factors of model (4) should contain the accounting data of the total amount of $P E$ (expenses accrued for environmental-protection purpose in a certain period ), the total amount of $P A$ (environmental-protection assets), TA(total assets) and so on.

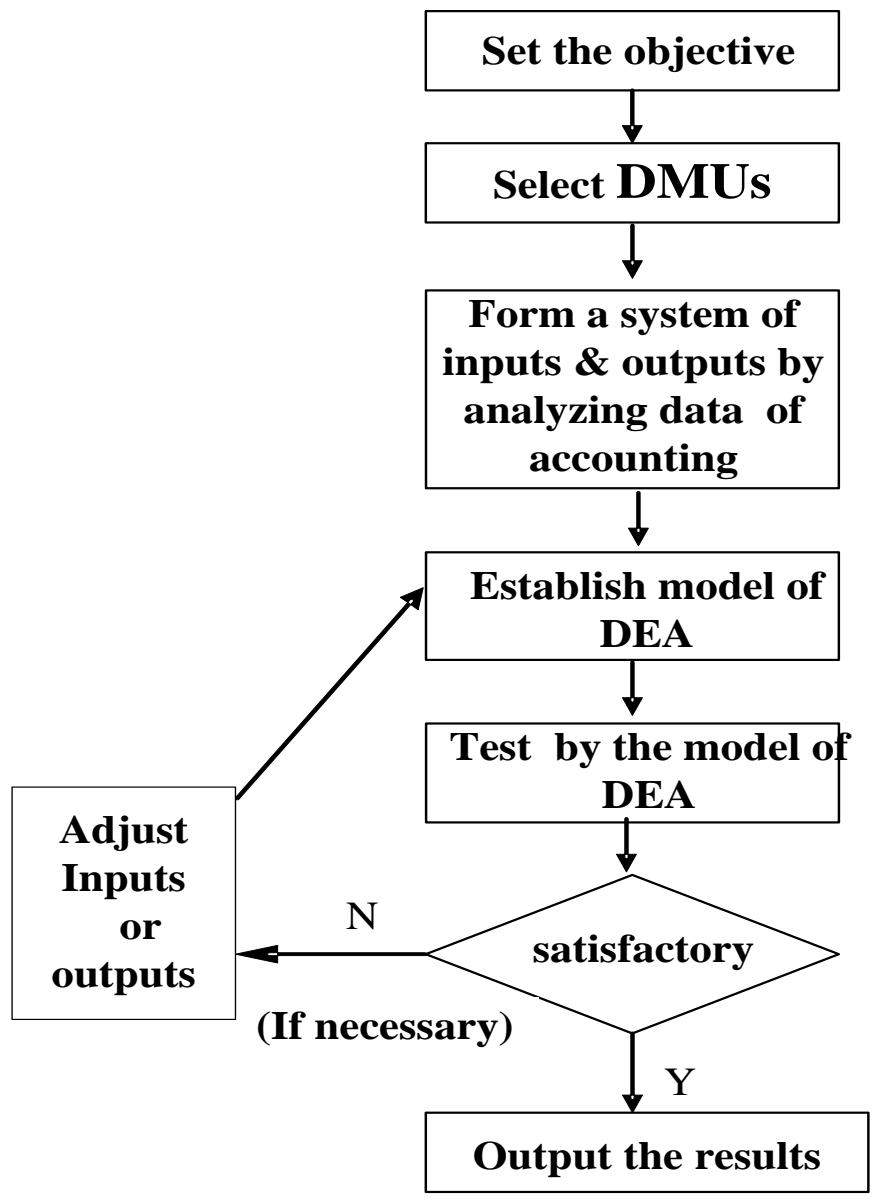

Fig. 1 Flow chart of DEA for evaluation system

The main output factors of model (4) should be the sum of $A L$ (environmental-pollution accident losses in production), $R R A$ (rate of return on environmental-protection assets), $E R$ (equity ratio) and so on, which deal with the firm's profitability. A Balance Sheet, an Income Statement or other financial reports of the thermal power plants should be analyzed or investigated to obtain the $P E$, $C A P, F A P$, TA and $A L$. The $P A$ includes the sum of $C A P$ (current assets for environmental-protection purpose) and the sum of FAP (fixed assets for environmental-protection purpose), the PA, RRA and $E R$ can be calculated by the following supplementary models of (1), (2) and (3) from the accounting data of financial reports of the thermal power plants. 


$$
\begin{gathered}
P A=\sum C A P+\sum F A P \\
R R A=\frac{I_{O}}{\left(T A_{b}+T A_{e}\right) / 2} \\
E R=\frac{O E_{e}}{T A_{e}}
\end{gathered}
$$

In these models of (1), (2) and (3):

$\sum C A P$ : Sum of current assets for environmental-protection purpose

$\sum F A P$ : Sum of fixed assets for environmental-protection purpose

$T A_{b}$ : Total assets at beginning of the certain period

$T A_{e}$ : Total assets at end of the certain period

$I_{0}$ : Operating Income (Income before interest expense and income tax)

$O E_{e}$ : Owner's Equity (period-end balance)

In the next model of (4), $x^{n}{ }_{i}, y_{j}^{n}$ means the No.i input and No.j output in No. $n$ unit, $v_{i}^{t}$, and $u_{j}^{t}$ are the weights of the No.i input factor of evaluating the environmental-protection resources invested and No.j output calculated by the model (4)

$$
\left\{\begin{array}{l}
\max z^{t}=\sum_{j=1}^{J} u_{j}^{t} y_{j}^{t} \\
\text { s.t. } \quad \sum_{i=1}^{I} v_{i}^{t} y_{i}^{t}=1 \\
\\
\quad \sum_{j=1}^{J} u_{j}^{t} y_{j}^{n}-\sum_{i=1}^{I} v_{i}^{t} x_{i}^{n} \leq 0 \\
n=1, \ldots, t, \ldots, N ; u_{j}^{t} \geq e ; v_{i}^{t} \geq e ; i=1, \ldots, I ; j=1, \ldots, J . .
\end{array}\right.
$$

The $e$ is infinitesimal and the code of unit of environmental-protection resources evaluated to ensure positive weight of all inputs and outputs. This model (4) meets thus a stipulation condition that no a unit of environmental-protection resources evaluated will more than $100 \%$ efficiencies or more than 1.0 ratios when coefficient of the same set of inputs and outputs is used to contrast with all other units. If the different $t$ values are put into this model (4) of mathematical programming, the $z^{t}\left(0<z^{t} \leq 1\right)$, efficiency of a Decision-Making Units of DEA, will be calculated, $z^{t}=1$ means that this decision-making units for evaluating the environmental-protection resources invested in the thermal power plants is effective and also means lower risks, $z^{t}<1$ means that this decision-making units is inefficiency for the safety resources invested in this thermal power plant also means higher risks. With the model (4) of $C^{2} R$, the availability of environmental-protection resources supplied in every thermal power plants can be evaluated on the basis of accounting input data and output data in one of the thermal power plants, and the range of economic risks of environmental-protection resources invested in the thermal power plants also be confirmed.

\section{Conclusions}

If enough resources of environmental protection have been efficiently invested to the thermal power plants for the ecological production by the thermal power plants, a win-win outcome would be formed. Environmental-protection resources invested are very important in operation of the thermal power plants, because if the process can be made more efficient and significant cost savings and reduction of environmental-pollution accidents can be achieved. The aim of this paper only provides a direction for the innovation of system of economic efficiency and helps the related units to make right decisions with the results of economic efficiency. 


\section{References}

[1] LIU Jin: Thermal power plant waste water zero-emission technology proposal (in Chinese), Huadian Technology, Vol. 39, Issue 9 (2017), p. 58-62

[2] ZHANG Qi and LIU Shi-Wei: Application of Modern Environmental Protection Technology in Thermal Power Plant (in Chinese), Chemical Engineering Design Communications, Vol. 43, Issue 4 (2017), p. 225-230

[3] WANG Chao: Environmental protection measures for coal-fired power plant (in Chinese), Shanxi Chemical Industry, Vol. 37, Issue 3 (2017), p. 138-139

[4] WANG Xi-Ping: Research on total factor energy efficiency of coal-fired power plant based on super-efficiency DEA(in Chinese ), Power Demand Side Management, Vol. 16, Issue 3 (2014), p. $18-23$

[5] YAN Qing-You and YIN Jie-Ting: Research on the Efficiency of Biomass Power Generation Industry Based on the Network DEA Model(in Chinese ), Operations Research and Management Science, Vol. 26, Issue 11 (2017), p. 120-128

[6] ZHAO Wen-Hui, ZHONG Kong-Lu ,MAO Lu and YE Dong: Research on economic benefits of wind power in three northern regions based on the ultra-efficiency(in Chinese ), Renewable Energy Resources, Vol. 34, Issue 3 (2016), p. 448-453 